\title{
Ballistic Limit Thickness and Weight of High Strength Fiber Fabrics for Sub-millimeter Steel Sphere Impact at $6 \mathrm{~km} / \mathrm{s}$
}

\author{
By Masumi Higashide ${ }^{1)}$, Naomi ONOSE $^{2)}$ and Sunao HaSEGAwA ${ }^{3)}$ \\ ${ }^{1)}$ Innovative Technology Research Center, Japan Aerospace Exploration Agency, Tokyo, Japan \\ ${ }^{2)}$ Graduate University for Advanced Studies, Sagamihara, Japan \\ ${ }^{3)}$ Institute of Space and Astronautical Science, Japan Aerospace Exploration Agency, Sagamihara, Japan
}

(Received June 20th, 2013)

\begin{abstract}
Sub-millimeter debris impact is a cause of mission failure for satellites in low earth orbit. To protect a satellite, important components whose failure can cause critical damage to the satellite should be installed inside the satellite structure. However, this is impossible for some components, e.g., expandable structures and wire harnesses. To protect these components, a flexible debris bumper is proposed in this study. The ballistic limits of fabric bumper shields made from high-strength fibers were investigated through hypervelocity impact experiments. Three types of Kevlar cloth, two types of Beta cloth, and three types of Nextel cloth were tested, and their ballistic limit thicknesses and weights were calculated. The Beta cloth was the thinnest bumper, and the high modulus Kevlar cloth was the lightest bumper. Fabric bumper shields required more thickness than a conventional aluminum bumper. However, they can reduce weight by $30-60 \%$ compared to aluminum.
\end{abstract}

Key Words: Debris Bumper Shield, Hypervelocity Impact, Fabric Bumper, Ballistic Limit

\section{Nomenclature}

C : Speed of sound in target $(\mathrm{km} / \mathrm{s})$

$d_{p} \quad: \quad$ projectile diameter $(\mathrm{mm})$

$H \quad$ : Brinell hardness of target

$t_{c} \quad:$ target perforation thickness $(\mathrm{cm})$

$t_{\text {fabric }}:$ thickness of fabric $(\mathrm{mm})$

$V_{f} \quad:$ fiber volume fraction in fabric

$v_{n} \quad:$ normal component of impact velocity $(\mathrm{km} / \mathrm{s})$

$v_{p} \quad:$ impact velocity $(\mathrm{km} / \mathrm{s})$

$\alpha_{\text {fabric }}:$ areal density of fabric $\left(\mathrm{kg} / \mathrm{m}^{2}\right)$

$\rho_{f} \quad:$ fiber density $\left(\mathrm{g} / \mathrm{cm}^{3}\right)$

$\rho_{p} \quad:$ projectile density $\left(\mathrm{g} / \mathrm{cm}^{3}\right)$

$\rho_{t} \quad:$ target density $\left(\mathrm{g} / \mathrm{cm}^{3}\right)$

\section{Introduction}

The impact of sub-millimeter space debris is a cause of mission failure for satellites in low earth orbit. Satellite developers must consider satellite protection and debris impact. JAXA has prepared standards and a handbook for debris protection design of unmanned spacecraft ${ }^{1}$. Important components related to satellite life and mission success are recommended to be installed inside the satellite structure. However, this is impossible for some components, e.g., expandable structures and wire harnesses. They are made of materials that are vulnerable to debris impact, and their damage can cause loss of control or mission failure. To protect these components, flexible structures are useful as debris bumpers. The authors propose a fabric bumper shield made of high-strength fiber. Fabric can be applied to a complex-shaped structure owing to its flexibility. Consequently, it can be expected to be applied as a bumper for expandable structures.

High-strength fiber fabric has been used in bulletproof jackets. Thus, there are many studies on low-velocity impacts on high-strength fiber fabrics ${ }^{2-6)}$. High-strength fiber fabrics are also known to be useful for protection against high-velocity impacts. Alamido or ceramic fiber fabrics are used as a part of the Staffed Whipple Bumper installed on the International Space Station ${ }^{7}$. However, data on submillimeter debris impact on high-strength fiber fabrics are not sufficient to justify their use as debris bumper shields. The purpose of this study is to test the ballistic limits of high-strength fiber fabrics against submillimeter debris impacts. Hypervelocity impact experiment results for alamido fiber (Kevlar produced by DuPont), glass fiber covered with polytetrafluoroethylene (Beta produced by Saint-Gobain), and ceramic fiber (Nextel produced by $3 \mathrm{M}$ ) are reported in the present paper.

\section{Hypervelocity Impact Experiment}

The properties of the tested fabrics are listed in Table 1 . Fabric density is the number of warp and woof yarns per inch. A higher value of fabric density is found in finer textiles. Two types of Kevlar cloth were compared: K29, which is a normal type, and $\mathrm{K} 49$, which is high-modulus type. The tensile strengths of both fibers are approximately 3,000 $\mathrm{MPa}$, but their tensile moduli are $71 \mathrm{GPa}$ (K29) and $112 \mathrm{GPa}$ (K49). Beta cloth is used as part of the multilayer insulation on the International Space Station. It is made from glass fiber covered with polytetrafluoroethylene (PTFE). Two types of Beta cloth were tested: normal cloth and cloth with an outer surface of evaporated aluminum. Nextel is made mainly from 
alumina, and it has high heat resistance with a melting temperature of approximately $1,800^{\circ} \mathrm{C}$. Nextel 440 can be used in hotter environments than Nextel 312. The mechanical properties of the fibers are listed in Table 2. E-glass is given instead of Beta. Approximately 10-mm-thick layers of fabric were stacked and installed in a test chamber as shown in Fig. 1. There was no standoff between the fabrics and the aluminum alloy plate. The top and bottom edges of the target were fixed.

Hypervelocity impact experiments were performed using a two-stage light gas gun at the Institute of Space and Astronautical Science of the Japan Aerospace Exploration Agency (ISAS/JAXA). According to the flux of $0.1-1 \mathrm{~mm}$ debris calculated using a debris environment model, alumina impacts most frequently on a spacecraft. Its average impact velocity is approximately $10 \mathrm{~km} / \mathrm{s}$. However, a feasible velocity for the two-stage light gas gun was only $7 \mathrm{~km} / \mathrm{s}$. Currently, there is no device capable of stably accelerating sub-millimeter solid spheres to $10 \mathrm{~km} / \mathrm{s}$. Therefore, this study used steel as the projectile material. The impact pressure was therefore increased owing to the increased projectile density. To investigate the damage caused by sub-millimeter debris impact, steel spheres $0.15,0.3$, and $0.5 \mathrm{~mm}$ in diameter were used as projectiles. The projectiles were launched in a scatter-shot. Many projectiles were put into a sabot and

Table 1. Properties of fabrics

\begin{tabular}{llllll}
\hline Fabric & Fiber & Weave & $\begin{array}{l}\text { Fabric } \\
\text { density } \\
\text { (yarns/inch) }\end{array}$ & $\begin{array}{l}\text { Areal } \\
\text { density } \\
\left(\mathrm{kg} / \mathrm{m}^{2}\right)\end{array}$ & $\begin{array}{l}\text { Thick- } \\
\text { ness } \\
(\mathrm{mm})\end{array}$ \\
\hline $\begin{array}{l}\text { Kevlar, } \\
\text { normal }\end{array}$ & K29 & Plain & $24 \times 24$ & 0.319 & 0.43 \\
$\begin{array}{l}\text { Kevlar, } \\
\text { high-modulus, } \\
\text { thin }\end{array}$ & K49 & Plain & $34 \times 34$ & 0.058 & 0.08 \\
$\begin{array}{l}\text { Kevlar, } \\
\text { high-modulus, } \\
\text { thick }\end{array}$ & K49 & Plain & $17 \times 17$ & 0.217 & 0.33 \\
$\begin{array}{l}\text { Beta cloth, } \\
\text { w/aluminum }\end{array}$ & Beta & Plain & $\begin{array}{l}\text { not } \\
\text { published }\end{array}$ & 0.274 & 0.203 \\
$\begin{array}{l}\text { Beta cloth, } \\
\text { w/o aluminum }\end{array}$ & Beta & Plain & $\begin{array}{l}\text { not } \\
\text { published }\end{array}$ & 0.274 & 0.177 \\
$\begin{array}{l}\text { Nextel, } \\
\text { normal }\end{array}$ & $\begin{array}{l}\text { Nextel } \\
\text { N12 }\end{array}$ & Plain & $30 \times 25$ & 0.305 & 0.406 \\
$\begin{array}{l}\text { Nextel, } \\
\text { normal, satin }\end{array}$ & $\begin{array}{l}\text { Nextel } \\
312\end{array}$ & Satin & $20 \times 17$ & 0.447 & 0.533 \\
$\begin{array}{l}\text { Nextel, } \\
\text { high-modulus, } \\
\text { satin }\end{array}$ & $\begin{array}{l}\text { Nextel } \\
440\end{array}$ & Satin & $30 \times 26$ & 0.500 & 0.508 \\
\hline
\end{tabular}

Table 2. Properties of fibers.

\begin{tabular}{|c|c|c|c|c|c|}
\hline Fiber & $\begin{array}{l}\text { Tensile } \\
\text { strength } \\
(\mathrm{MPa})\end{array}$ & $\begin{array}{l}\text { Tensile } \\
\text { modulus } \\
(\mathrm{GPa})\end{array}$ & $\begin{array}{l}\text { Density } \\
\left(\mathrm{g} / \mathrm{cm}^{3}\right)\end{array}$ & $\begin{array}{l}\text { Breaking } \\
\text { elongation } \\
(\%)\end{array}$ & $\begin{array}{l}\text { Melting } \\
\text { temper- } \\
\text { ature } \\
\left({ }^{\circ} \mathrm{C}\right)\end{array}$ \\
\hline K29 & 2920 & 70.5 & 1.44 & 3.6 & 538 \\
\hline K49 & 3000 & 112.4 & 1.45 & 2.4 & 538 \\
\hline (E-glass) & (3200) & (78) & (2.6) & $(4.8)$ & (844) \\
\hline $\begin{array}{l}\text { Nextel } \\
312\end{array}$ & 1700 & 150 & 2.7 & 1.2 & 1800 \\
\hline $\begin{array}{l}\text { Nextel } \\
440\end{array}$ & 2000 & 190 & 3.05 & 1.1 & 1800 \\
\hline
\end{tabular}

accelerated at the same time. The average number of impacting projectiles per shot was 55.2 for $d_{p}=0.15 \mathrm{~mm}, 19.3$ for $d_{p}=0.3 \mathrm{~mm}$, and 8.3 for $d_{p}=0.5 \mathrm{~mm}$.

\section{Experimental Result}

The total data numbers obtained from the impact experiments are listed in Table 3. The Nextel fabrics were tested using only 0.15 and $0.3 \mathrm{~mm}$ projectiles. The average impact velocity was $6.06 \mathrm{~km} / \mathrm{s}$. Examples of targets after impact are shown in Figs. 2-4. The projectiles perforated the 1 st layer, and then they broke up. The fragment clouds were stopped in the middle layer. Impacted yarn in the fabric was broken by the fragment. In this study, the ballistic limit was defined as nonperforation by the projectile fragments, as shown in Fig. 5. From the ballistic limit layers of the fabrics, the ballistic limit thickness and weight were calculated by the thickness and areal density per layer.

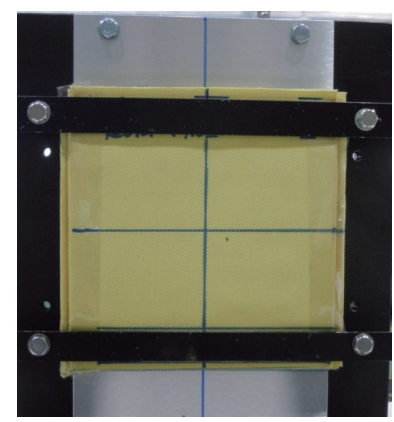

Fig. 1. Target fixed on an aluminum alloy plate.

Table 3. Total data number of impacting projectiles.

\begin{tabular}{llcc}
\hline Fabric & $\begin{array}{l}d_{p} \\
(\mathrm{~mm})\end{array}$ & $\begin{array}{l}\text { Average } \\
v_{p}(\mathrm{~km} / \mathrm{s})\end{array}$ & $\begin{array}{c}\text { Data } \\
\text { number }\end{array}$ \\
\hline Kevlar, normal & 0.15 & 6.11 & 51 \\
Kevlar, normal & 0.3 & 5.89 & 10 \\
Kevlar, normal & 0.5 & 5.81 & 9 \\
Kevlar, high-modulus, thin & 0.15 & 5.95 & 53 \\
Kevlar, high-modulus, thin & 0.3 & 6.23 & 22 \\
Kevlar, high-modulus, thin & 0.5 & 6.17 & 11 \\
Kevlar, high-modulus, thick & 0.15 & 6.14 & 131 \\
Kevlar, high-modulus, thick & 0.3 & 6.27 & 31 \\
Kevlar, high-modulus, thick & 0.5 & 6.13 & 14 \\
Beta cloth, w/aluminum & 0.15 & 5.92 & 42 \\
Beta cloth, w/ aluminum & 0.3 & 6.13 & 12 \\
Beta cloth, w/ aluminum & 0.5 & 6.10 & 3 \\
Beta cloth, w/o aluminum & 0.15 & 5.98 & 84 \\
Beta cloth, w/o aluminum & 0.3 & 6.07 & 27 \\
Beta cloth, w/o aluminum & 0.5 & 6.00 & 29 \\
Nextel, normal & 0.15 & 5.75 & 57 \\
Nextel, normal & 0.3 & 5.93 & 49 \\
Nextel, normal, satin & 0.15 & 6.21 & 28 \\
Nextel, normal, satin & 0.3 & 6.06 & 51 \\
Nextel, high-modulus, satin & 0.15 & 6.15 & 95 \\
Nextel, high-modulus, satin & 0.3 & 6.04 & 63 \\
\hline & & & \\
\hline
\end{tabular}



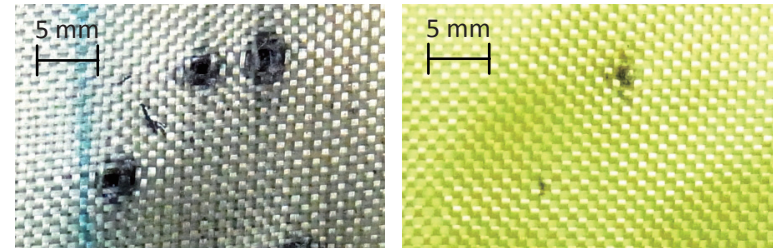

Fig. 2. Impacted Kevlar cloth (high-modulus, thin), $d_{p}=0.5 \mathrm{~mm}$,

$v_{p}=6.26 \mathrm{~km} / \mathrm{s}$. (left) $1 \mathrm{st}$ layer. (right) $53 \mathrm{rd}$ layer.

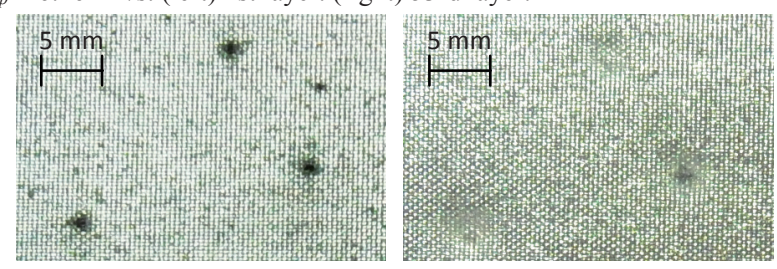

Fig. 3. Impacted Beta cloth covered with evaporated aluminum, $d_{p}=0.5 \mathrm{~mm}, v_{p}=6.10 \mathrm{~km} / \mathrm{s}$. (left) $1 \mathrm{st}$ layer. (right) 15 th layer.

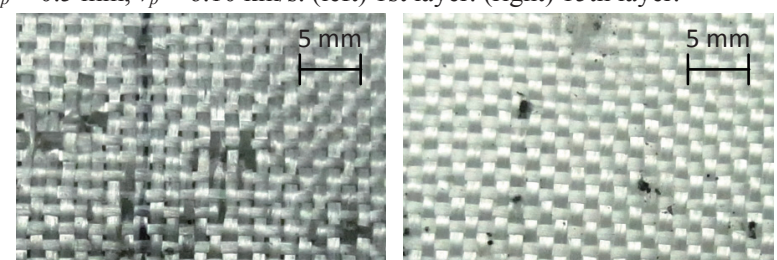

Fig. 4. Impacted Nextel cloth (normal), $d_{p}=0.3 \mathrm{~mm}, v_{p}=6.08 \mathrm{~km} / \mathrm{s}$. (left) 1st layer. (right) 10th layer.

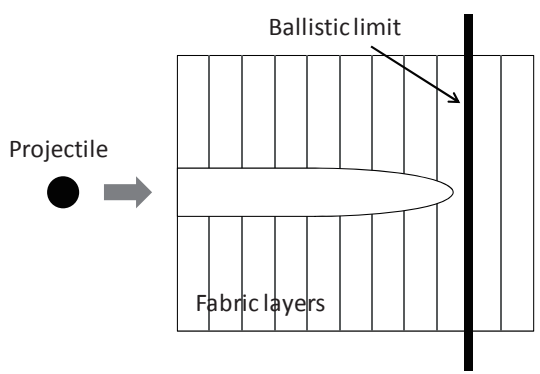

Fig. 5. Definition of ballistic limit of fabric bumper.

\subsection{Ballistic limit thickness}

A comparison of the ballistic limit thicknesses is shown in Fig. 6. The value of $3 \sigma$ was used for the error bars. Normal Beta cloth was the thinnest bumper. From the comparison of the same type of fiber, the fabric made from high-modulus fiber seemed to show good performance as a debris bumper. If the fiber is the same, stacking many thin fabric layers is effective in improving protection capability.

The relationship between the ballistic limit thickness at $d_{p}=$ $0.3 \mathrm{~mm}$ and the tensile strength of the fiber is shown in Fig. 7. The tensile strength of E glass was plotted as the value for Beta cloth because the mechanical properties of the glass fiber covered with PTFE were not published. With an increase in tensile strength, the ballistic limit thickness decreased. As shown in Figs. 2-4, the fibers in the 1st layer were simply cut, whereas the layers near the ballistic limit were deformed around the perforated hole. Therefore, the effect of tensile strength appears to contribute to ballistic performance when the velocity of the projectile fragments is decreased in the layers near the ballistic limit.

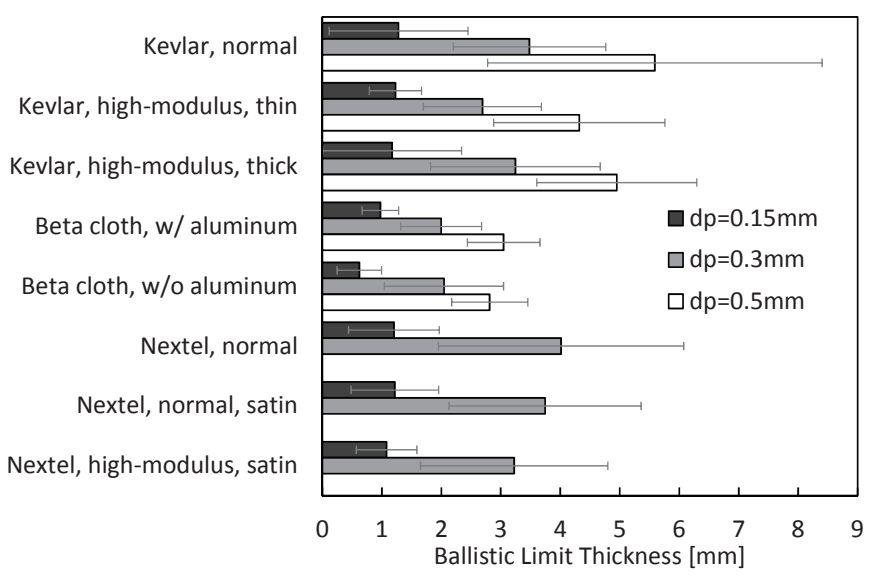

Fig. 6. Ballistic limit thickness of fabric bumpers.

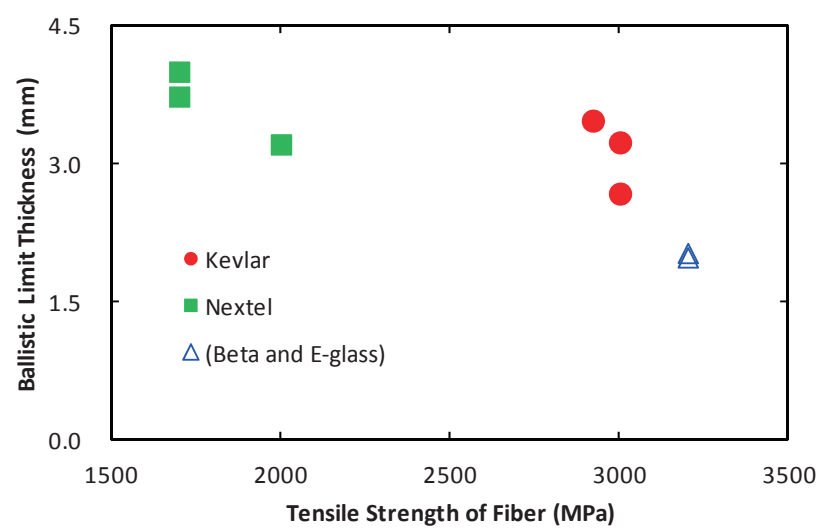

Fig. 7. Relationship between tensile strength of fiber and ballistic limit thickness of fabric bumper, $d_{p}=0.3 \mathrm{~mm}$.

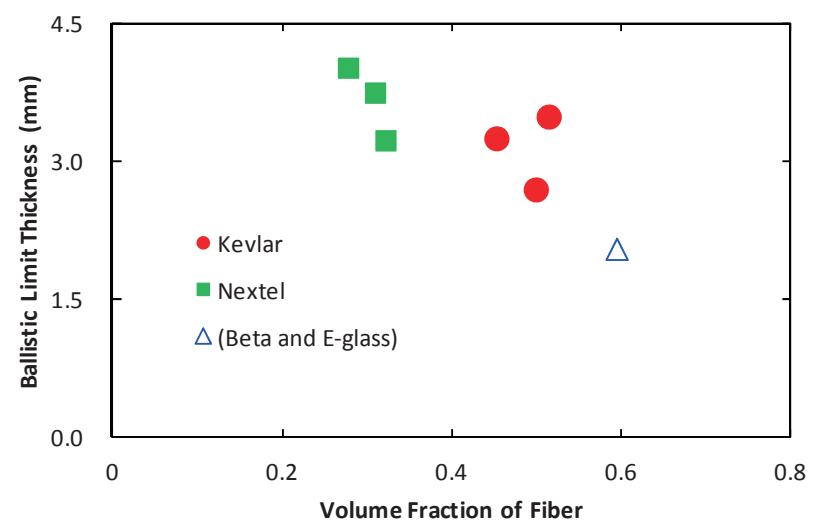

Fig. 8. Relationship between volume fraction of fiber in fabric and ballistic limit thickness of fabric bumper, $d_{p}=0.3 \mathrm{~mm}$.

The fiber volume fraction in the fabric was calculated. If the weight of a fabric is equal to the weight of the fibers contained in the fabric, the fiber volume fraction is written as

$$
V_{f}=\frac{\alpha_{\text {fabric }}}{\rho_{f} t_{\text {fabric }}}
$$

The calculation results are shown in Fig. 8. For the Beta cloth, the value for only normal type was taken as the fiber density of E-glass. If a thinner debris bumper is needed, it is recommended that the fabric include many fibers. 


\subsection{Ballistic limit weight}

Next, a comparison of ballistic limit thicknesses is shown in Fig. 9. The value of $3 \sigma$ was used for the error bars. Thin Kevlar cloth made from K49 was the lightest bumper. Kevlar showed a difference between K29 and K49, but no significant difference was observed among the Nextel cloths.

The relationship between the ballistic limit thickness at $d_{p}=$ $0.3 \mathrm{~mm}$ and the fiber density is shown in Fig. 10. A lower-density fiber seems useful as fabric debris bumper material.

\section{Comparison with an Aluminum Bumper}

To assess the usability of the fabric bumper shields, their ballistic limits were compared with a monolithic aluminum bumper. The ballistic limit of the monolithic aluminum bumper was calculated from an empirical equation published by E. Christiansen, 2003 ${ }^{7}$. Christiansen's equation is shown in Eqs. (2) and (3):

when $\rho_{p} / \rho_{t}<1.5$

$$
t_{w}=1.8 \times 5.24 d^{19 / 18} H^{-0.25}\left(\frac{\rho_{p}}{\rho_{t}}\right)^{1 / 2}\left(\frac{v_{n}}{C}\right)^{2 / 3}
$$

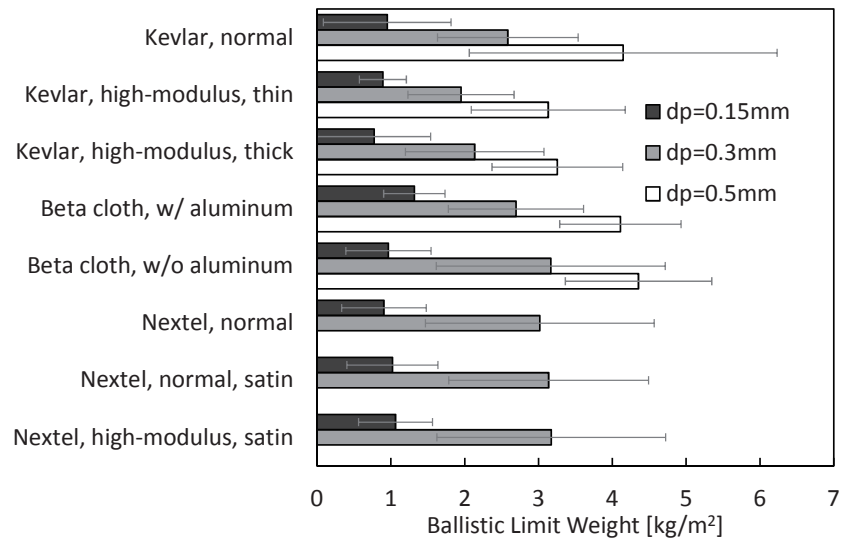

Fig. 9. Ballistic limit weight of fabric bumpers.

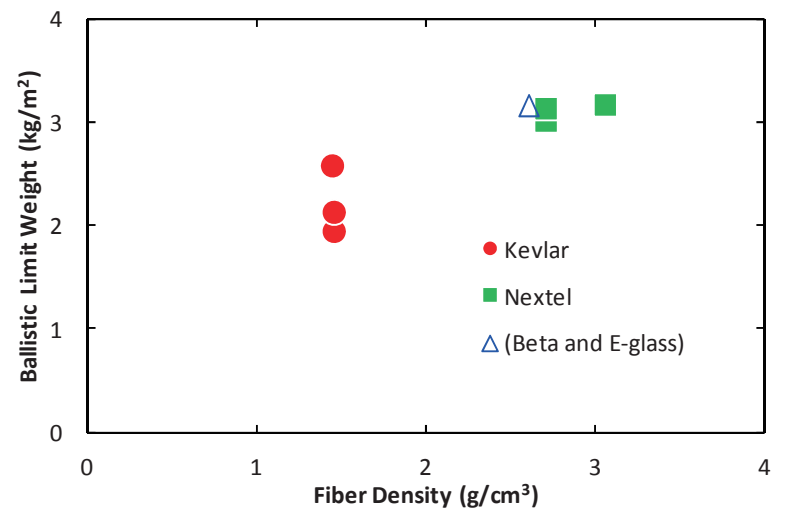

Fig. 10. Relationship between fiber density and ballistic limit thickness of fabric bumpers, $d_{p}=0.3 \mathrm{~mm}$. and when $\rho_{p} / \rho_{t} \geq 1.5$,

$$
t_{w}=1.8 \times 5.24 d^{19 / 18} H^{-0.25}\left(\frac{\rho_{p}}{\rho_{t}}\right)^{2 / 3}\left(\frac{v_{n}}{C}\right)^{2 / 3}
$$

Because the projectile is steel and the target is the high-strength fabrics, Eq. (3) was used for the calculation.

The comparison results are shown in Figs. 11 and 12 where the vertical axes represent the ballistic limit thickness and weight, respectively, of the fabric bumpers divided by those of a monolithic aluminum bumper calculated from Eq. (3). If the value is less than unity, the fabric is more effective as a debris bumper than an aluminum plate. In Fig. 11, the fabric bumpers did not become thinner than an aluminum bumper. The Beta cloth bumper is considered to have a similar thickness to an

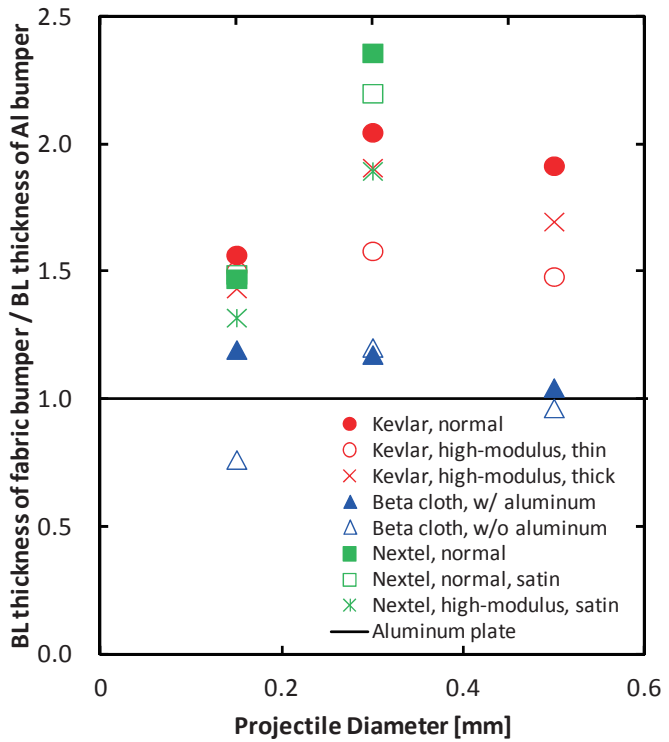

Fig. 11. Ballistic limit thickness of fabric bumpers divided by ballistic limit thickness of monolithic aluminum bumper.

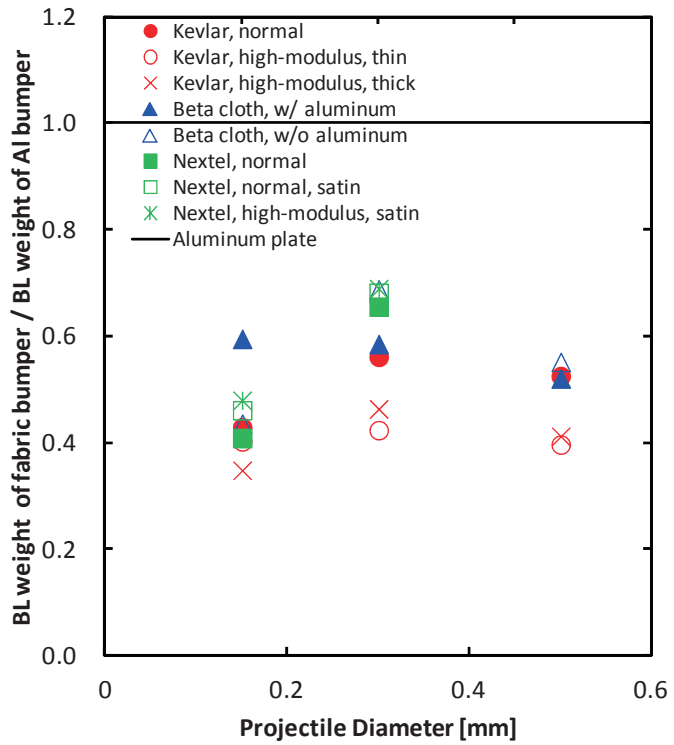

Fig. 12. Ballistic limit weight of fabric bumpers divided by ballistic limit weight of monolithic aluminum bumper. 
aluminum bumper. However, the Kevlar and Nextel bumpers needed to be approximately 2 and 2.5 times thicker, respectively, than an aluminum bumper. Fabric bumpers are flexible, but they require thicker structures. However, the ballistic limit weights of the fabric bumpers are significantly less than aluminum as shown in Fig. 12. The lightest bumper was Kevlar. Its weight can be $30 \%$ that of aluminum. The weights of the Beta cloth and Nextel bumpers were approximately 0.6 and 0.5 times that of an aluminum bumper, respectively.

\section{Summary}

To propose a flexible debris bumper shield, three types of Kevlar cloth, two types of Beta cloth, and three types of Nextel cloth were investigated by hypervelocity impact experiments. The protection capabilities of the fabric bumpers were assessed according to ballistic limit thickness and weight.

Beta cloth was the thinnest bumper, and Kevlar cloth made from high-modulus fiber was the lightest bumper. Using a fiber with a higher tensile strength and modulus was effective for producing thinner bumpers. The bumper thickness was decreased by stacking thinner fabrics and by using fabrics with a higher fiber volume fraction. Lower-density fiber decreased the bumper weight. The Beta cloth bumper had a thickness similar to that of an aluminum bumper, but its weight was approximately $60 \%$ that of aluminum. The Kevlar cloth bumper needed twice the thickness compared to an aluminum bumper, but its weight was only $30 \%$ that of aluminum.

\section{Acknowledgments}

This work was supported by the Space Plasma Laboratory, ISAS, JAXA. The authors acknowledge the valuable advice from the members of JAXA Spacecraft Design Standard Working Group 3.

\section{References}

1) JAXA Debris Protection Design Standard WG, Micro Debris Impact Risk Assessment Standard, JAXA Spacecraft Design Standard, JERG-2-144, 2012. (in Japanese)

2) Duan, Y., Keefe, M., Wetzel, E. D., Bogetti, T. A., Powers, B., Kirkwood, J. E., Kirkwood, K. M.: Effects of friction on the ballistic performance of a high-strength fabric structure, Proceedings of International Conference on Impact Loading of Lightweight Structure, 2005.

3) Yen, C. F., Scott, B., Dehmer, P., Cheeseman, B.: A comparison between experiment and numerical simulation of fabric ballistic impact, Proceedings of 23rd International Symposium on Ballistics, (2007), pp. 853-864.

4) Zhang, G. M., Batra, R. C., Zheng, J.: Effect of frame size, frame type, and clamping pressure on the ballistic performance of soft body armor, Composites, Part B 39 (2008), pp. 476-489.

5) Nilakantan, G., Keefe, M., Gillespie Jr., J. W., Bogetti, T. A.: Novel multi-scale modeling of woven fabric composites for use in impact studies, Proceedings of $10^{\text {th }}$ International LS-DYNA User Conference, (2008), pp. 19-38.

6) Pereira, J. M., Roberts, G. D., Revilock, D. M.: Elevated temperature ballistic impact testing of PBO and Kevlar fabrics for application in supersonic jet engine fan containment systems, NASA TM, 107532, 1997.

7) Christiansen, E. L.: Meteoroid/Debris Shielding, NAXA TP, 201788, 2003. 